\begin{tabular}{lll}
\hline Volume : 1 & No : 2 November 2016 & ISSN : 2502 - 7069 \\
\hline
\end{tabular}

\title{
PENGARUH KEPEMIMPINAN TRANSFORMASIONAL KEPALA SEKOLAH TERHADAP KINERJA GURU SEKOLAH MENENGAH ATAS DI KABUPATEN SUMBA BARAT DAYA NTT
}

\author{
Oleh : \\ Mikael Sene \\ Dosen PGSD STKIP Weetebula, Sumba Barat Daya, NTT \\ Mikhael.sene@yahoo.com
}

\begin{abstract}
Abstrak: Penelitian ini bertujuan untuk mengetahui pengaruh kepemimpinan kepala sekolah terhadap kinerja guru.

Penelitian ini menggunakan pendekatan kuantitatif dengan jenis penelitian korelasional yaitu menentukan adanya pengaruh dan besarnya kontribusi variabel kepemimpinan kepala sekolah terhadap variabel kinerja guru. Populasi penelitian adalah 279yang terdiri dari kepala sekolah dan para guru SMA di Kabupaten Sumba Barat Daya NTT. Sampel sejumlah 120 orang dengan teknik proportional random sampling. Pengumpulan data menggunakan metode kuisioner. Uji reliabilitas dengan metode Alpha-Cronbach.Analisis data menggunakan teknik regresi linear sederhana. Hasil penelitian menunjukkan sebagai berikut. Hasil analisis regresi linear sederhana menunjukkan ada pengaruh positif yang signifikan antara kepemimpinan kepala sekolah terhadap kinerja guru ( $\left.<<0,05 ; \mathrm{R} \_\mathrm{YX} 1 \wedge 2=46,3 \%\right)$.
\end{abstract}

Kata Kunci: Kepemimpinan Transformasional Kepala Sekolah, Kinerja Guru.

Abstractk: This study aimed to revealthe effect of school leadership on the performance of the teachers. The quantitative corelational approach was used in this research for determining any effect and how big the contribution of the school leadership and school climate variable on teacher performance variable. There were 279 respondents as the population which consisted of the principals and the teachers of senior high schools in Sumba Barat Daya Regency NTT. A sample of 120 teachers was established using the proportional random sampling. The data were collected using a questionnaire. Whereas for the reliability test, Alpha-Cronbach method was used. The data were analysed using single linearity regression techniques. The results of the study are as follows. The single linearity regression analysis of the study shows that there is a significant positive effect of the school leadership on teachers' performance $(p<0.05$; $\left.R_{-} Y X 1^{\wedge} 2=46.3 \%\right)$.

Keywords: school Leadership, Teacher Performance. 


\section{PENDAHULUAN}

Pendidikan pada hakikatnya adalah usaha membudayakan manusia atau usaha memanusiakan manusia muda agar menjadi lebih manusiawi (Dick Hartoko, 1987: 10). Artinya, pendidikan merupakan suatu proses pemaknaan terhadap eksistensi manusia agar manusia semakin menyadari hakikat hidup yang sesungguhnya. Proses pemaknaan ini ditempuh melalui pembentukan dan pengembangan kepribadian, intelektual, perilaku, kecerdasan spiritual dan emosional secara seimbang.

Pandangan tersebut di atas sejalan dengan penegasan dalam Undang-Undang Nomor 20 Tahun 2003 tentang Sistem Pendidikan Nasiona Pasal 1 ayat 1, yang merumuskan bahwa pendidikan merupakan usaha sadar dan terencana untuk mewujudkan suasana belajar dan proses pembelajaran agar peserta didik secara aktif mengembangkan potensi dirinya untuk memiliki kekuatan spiritual keagamaan, pengendalian diri, kepribadian, kecerdasan, akhlak mulia, serta keterampilan yang diperlukan dirinya, masyarakat, bangsa dannegara. Oleh karenaitu, pendidikan berfungsi untuk mengembangkan kemampuan dan membentuk watak serta peradaban bangsa yang bermartabat, dalam rangka mencerdaskan kehidupan bangsa, bertujuan untuk berkembangnya potensi peserta didik agar menjadi manusia yang beriman dan bertakwa kepada Tuhan Yang Maha Esa, berakhlak mulia, sehat, berilmu, cakap, kreatif, mandiri, dan menjadi warga negara yang demokratis serta bertanggung jawab.

Cita-cita luhur pendidikan Indonesia seperti yang dipaparkan di atas belum mampu terwujud maksiamal di Kabupaten Sumba Barat Daya. Realitas mutu pendidikan di
Kabupaten Sumba Barat Daya masih sangat rendah.Berdasarkan hasil ujian Nasional tingkat SMA/SMK tahun 2012, provinsi Nusa Tenggara Timur merupakan provinsi dengan tingkat kelulusan terendah dibandingkan dengan seluruh provinsi lain di Indonesia yaitu dengan persentase kelulusan 95,50\%, pada ujian nasional tahun 2011 untuk SMA/SMK hanya 94,45 dan pada ujian nasional tahun 2010 untuk SMA/SMK hanya 48,04 \% untuk ujian utama dan $89,72 \%$ saat ujian ulangan. Kabupaten Sumba Barat Daya pada tahun ajaran 2010 persentase kelulusan menempati peringkat ke-19 dari 20 kabupaten/kota yang ada di NTT, pada tahun ajaran 2011 berada pada peringkat ke-5 dari 21 kabupaten/kota yang ada di provinsi NTT, dan pada tahun 2012 Kabupaten Sumba Barat Daya termasuk salah satu kabupaten dari tiga kabupaten yang lulus 100\%. (http://www.wartasemesta.com/ un-smasmk-2012-ntt-raih-posisi-terakhir).

Indikator lain dari masalah rendahnya kualitas sumber daya manusia warga Sumba Barat Daya tergambar pada kehidupan masyarakat yang masih sangat natural dan destruktif yang termanifestasi dalam masalah pengangguran, pola pertanian dan ternak yang masih tradisional, kasus pencurian dan perampokan yang terjadi di mana-mana, pola budaya yang konsumtif, tingginya remaja wanita yang menjadi tenaga kerja di luar negeri atau luar daerah, dll.

Berhadapan dengan masalah aktual rendahnya mutu pendidikan di Kabupaten Sumba Barat Daya, siapakah yang harus bertanggung jawab?Bagaimana harus dilakukan agar lembaga pendidikan menjadi lembaga human investment?Saiful Bahri (2010: 1) kembali menegaskan bahwa masalah mutu pendidikan tersebut tidak dapat ditumpukkan pada satu pihak, melainkan 
menjadi tanggung jawab semua pihak, baik langsung maupun tidak langsung dalam proses belajar mengajar, seperti guru, siswa, kepala sekolah, orang tua, pemerintah, organisasi sekolah, fasilitas belajar dan faktorfaktor lainnya. Syaiful Sagala (2009: iii) juga menegaskan bahwa pendidikan adalah karya bersama yang berlangsung dalam suatu pola kehidupan insani tertentu dan suatu sistem yang dikelompokkan menjadi dua sistem yakni sistem mekanik dan sistem organik. Di antara sejumlah faktor yang berperan, guru dan kepala sekolah merupakan pihak yang paling berperan dalam menentukan baik buruknya mutu pendidikan atau tercapai tidaknya tujuan pendidikan di tingkat satuan pendidikan.

Ngainun Naim(2009:3-4) menegaskan guru merupakan sosok penting yang cukup menentukan dalam proses pembelajaran, walaupun sekarang ini ada berbagai sumber belajar alternatif yang lebih kaya, seperti buku, jurnal, majalah, internet maupun sumber belajar lainnya, tetapi toh guru tetap menjadi kunci untuk optimalisasi sumber-sumber belajar yang ada. Jadi, bukan hal yang terlalu berlebihan jika ada penilaian bahwa berhasil atau tidaknya proses pendidikan tergantung pada peranan guru. Peran mulia profesi keguruan secara ideal sudah dirumuskan dalam Undang-Undang Nomor 14 Tahun 2005 (bab 1, pasal 1, ayat (1) tentang Guru dan Dosen, bahwa guru adalah pendidik profesional dengan tugas utama mendidik, mengajar, membimbing, mengarahkan, melatih dan mengevaluasi peserta didik pada pendidikan usia dini jalur pendidikan formal, pendidikan dasar, dan pendidikan menengah.

Peran ideal ini mesti diemban dengan performance yang optimal.Profesionalitas seorang guru dibuktikan dengan memiliki 1) kualifikasi akademik S1 atau D4, 2) memiliki keempat kompetensi guru. Peraturan Pemerintah No. 78 Tahun 2008, menyebutkan empat kompetensi guru yaitu kompetensi pedagogik, kompetensi kepribadian, kompetensi sosial, dan kompetensi professional, dan 3) memiliki sertifikat mengajar.

Berbicara tentang kinerja guru di Kabupaten Sumba Barat Daya, harus diakui masihterjadikesenjangan, yaituantaraapayang diharapkan dan apa yang menjadi kenyataan. Masih ada sekian banyak guru yang tidak memenuhi syarat kualifikasi yang menjadi salah satu kriteria guru profesional. Menurut Klemens Meba, Sekretaris Dinas Pemuda dan Olah Raga Provinsi Nusa Tenggara Timur, ada 63 persen guru di Provinsi Nusa Tenggara Timur masih berijazah SLTA dan D3 yang tidak memenuhi syarat kualifikasi pendidikan secara nasional untuk menjadi seorang guru dan secara khusus di Kabupaten Sumba Barat Daya, masih ada beberapa guru yang mengajar tidak sesuai dengan bidang keahliannya. Dari 120 orang guru sekolah menengah atas di 6 sekolah, diperkirakan guru yang mengajar tidak sesuai bidang keahliannya sebanyak 20 orang $(16,7 \%)$. Dari 120 orang guru yang menjadi sampel penelitian ditemukan ada 2 orang guru $(1,7 \%)$ berijazah SMK dan 20 orang guru $(16,7 \%)$ berijazah diploma. Ini berarti masih ada 22 orang guru (18,3\%) yang belum memenuhi syarat kualifikasi akademik mengajar di SMA.

Berdasarkan pengalaman peneliti yang pernah tinggal di Sumba selama empat tahun, peneliti mendengar dan melihat keluhan dari kepala sekolah tentang guru yang belum secara teratur menyiapkan rencana pelaksanaan pembelajaran (RPP) sesuai dengan standar kompetensi dan kompetensi dasar serta mengimplementasikan RPP 
dalam pembelajaran di kelas dengan baik. Gurukurang konsisten dalam mempersiapkan rencana pelaksanaan pembelajaran dan mengimplementasikannya di kelas.

Berdasarkan wawancara dengan Bapak Kepala Sekolah SMA Negeri Wewewa Selatan pada tanggal 8 Maret 2012, dikatakan bahwa masih banyak guru di sekolahnya yang tidak datang ke sekolah, terlebih pada akhir bulan.Masih banyak guru yang kurang disiplin dalam memulai dan mengakhiri pembelajaran di kelas (masuk kelas terlambat dan pulang lebih awal), masih banyak guru yang belum mempunyai kompetensi pedagogik dan akademikyang baik, dan mengajar lebih banyak menggunakan metode ceramah. Guru kurang kreatif dalam mengelola proses pembelajaran di kelas sehingga membuat siswa cepat jenuh dan kurang cepat berkembang, baik dalam hal kognitif, afeksi maupun psikomotornya. Apa yang dikemukakan oleh Kepala Sekolah SMA Negeri Wewewa Selatan ini, sejauh pengamatan peneliti, boleh dikatakan hal tersebut merupakan kenyataan umum bagi kebanyakan guru di seluruh sekolah menengah atas di Kabupaten Sumba Barat Daya.

Kondisi kinerja guru yang belum memuaskan saat ini merupakan tantangan bagi semua pihak untuk selalu berusaha mencari jalan sebagai upaya peningkatan kinerja guru menuju terciptanya guru-guru profesional. Selain apa yang telah dilakukan oleh pemerintah melalui kebijakan sertifikasi guru, bahwa untuk terciptanya kualitas kinerja guru yang profesional di sebuah sekolah dibutuhkan dukungan dan peranan kepala sekolah yang kompeten sebagai leader dan manager.

Kepala sekolah merupakan pihak yang paling berperan dalam menentukan baik buruknya mutu pendidikan karena merupakan figur sentral yang memiliki peran paling strategis dalam sekolah.Keberhasilan pendidikan sangat ditentukan oleh keberhasilan kepala sekolah dalam mengelola tenaga pendidik yang tersedia di sekolah.Kepala sekolah merupakan salah satu komponen pendidikan yang berpengaruh dalam meningkatkan kinerja guru.Kepala sekolah bertanggung jawab atas penyelenggaraan kegiatan pendidikan, administrasi sekolah, pembinaan tenaga kependidikan lainnya, dan pendayagunaan serta pemeliharaan sarana dan prasarana.

Kepala sekolah sebagai pimpinan tertinggi yang sangat berpengaruh dan menentukan kemajuan sekolah harus memiliki kemampuan administrasi, memiliki komitmen tinggi, dan luwes dalam melaksanakan tugasnya.Kepemimpinan kepala sekolah yang baik harus dapat mengupayakan peningkatan kinerja guru melalui program pembinaan kemampuan tenaga pendidik.Oleh karena itu, kepala sekolah harus mempunyai kepribadian atau sifat-sifat dan kemampuan serta keterampilan-keterampilan untuk memimpin sebuah lembaga pendidikan. Dalam perannya sebagai seorang pemimpin, kepala sekolah harus dapat memperhatikan (peka) akan kebutuhan dan perasaan para guru sehingga kinerja guru selalu terjaga.

Namun, sejalan dengan peran vital kepala sekolah tersebut, realitas di Kabupaten Sumba Barat Daya menunjukkan fenomena yang kurang menggembirakan, yakni masih banyak kepala sekolah yang belum memperlihatkan kinerja optimalnya. Afirmasi ini dapat dibuktikan antara lain dari mutu pendidikan yang dari tahun ke tahun cenderung stagnan atau tidak mengalami kemajuan yang berarti. Hal itu menandakan bahwa performance kepemimpinan kepala 
sekolah belum mampu meningkatkan kinerja guru.

Berdasarkan diskusi dengan Ketua Yayasan Pendidikan Nusa Cendana Sumba, Marcel Pingge Lamunde, pada tanggal 1-2 Maret 2012, beliau mengatakan bahwa sejauh pengamatan dan pengeluhan yang didengarnya dari para guru SMA, banyak kepala SMA yang belum mampu mengimplementasikan kompetensinya sebagai kepala sekolah di sekolahnya dengan baik, juga para kepala sekolah belum menjalankan tugas dan fungsinya secara maksimal, yaitu sebagai ed ucator,manager,administrator,supervisor,lead er, innovator, dan motivator.

Karena masalah-masalah faktual sebagaimana yang telah dipaparkan di atas, maka peneliti terdorong untuk melakukan sebuah penelitian lebih lanjut. Penelitian ini diberi judul Pengaruh Kepemimpinan Kepala Sekolah terhadap Kinerja Guru SMA di Kabupaten Sumba Barat Daya Provinsi Nusa Tenggara Timur.

\section{METODE}

Penelitian ini termasuk jenis penelitian korelasional.Desain yang dipilih adalah ex post facto, yaitu menggunakan data dari semua fakta yang telah terjadi.Berdasarkan jenis data dan teknik analisisnya penelitian ini termasuk jenis penelitian kuantitatif. Populasi dalam penelitian ini adalah para guru dan kepala sekolah yang bekerja pada 9 sekolah menengah atas negeri dan swasta di Kabupaten Sumba Barat Daya Provinsi NTT. Karena luasnya jangkauan antara kesembilan sekolah dan besarnya jumlah populasi, maka responden dalam penelitian ini menggunakan sampel. Pengambilan sampel dari populasi yang ada dilaksanakan dengan menggunakan proportional stratified random sampling.
Teknik ini digunakan untuk mendapatkan sampel acak dari populasi SMA yang berstrata menurut peringkat UN tahun 2010 dan jumlah guru yang berbeda-beda pada setiap SMA. Standarisasi sekolah ditentukan berdasarkan peringkat ujian nasional tahun 2010, bukan tahun 2011 karena persentase kelulusan tahun 2011 kebanyakan menjadi tinggi (baik), karena perubahan sistem kewenangan sekolah 40\% dan kewenangan pemerintah $60 \%$ ). Berdasarkan pertimbangan strata, maka seluruh SMA di Kabupaten Sumba Barat Daya dibagi ke dalam tiga kelompok.Kelompok peringkat atas terdiri atas tiga SMA, kelompok peringkat menengah terdiri atas tiga SMA, dan kelompok peringkat bawah terdiri atas tiga SMA.Selanjutnya, untuk masing-masing kelompok ditentukan secara acak dua SMA melalui undian, sehingga menjadi sampel kelompok sekolah peringkat atas, peringkat menengah, dan peringkat rendah, dengan jumlah enam SMA sebagai sampel penelitian. Selanjutnya, mengingat jumlah guru di setiap sekolah berbeda-beda, maka untuk sampel jumlah guru ditentukan juga dengan teknik proportional stratified random sampling.

\section{TEKNIK ANALISIS DATA}

\section{Uji Persyaratan Analisis}

a. Uji Normalitas

Joko Sulistyo (2010: 50) mengatakan uji normalitas digunakan untuk mengetahui apakah suatu data berdistribusi normal atau tidak. Untuk mengetahui data normal atau tidak bisa digunakan beberapa cara di antaranya adalah kolmogorov smirnov, shapiro wilk, lilliefors, nilai skewness dan histogram display normal kurve. Dalam penelitian ini penulis menggunakan uji statistik kolmogorov smirnov test dan grafik Q-Q Plots.Menurut 
Field (2009: 147), jika Asymp. Sig (2-tailed) $>0,05$, maka variabel bersifat normal.

\section{b. Uji Liniaritas}

Tujuan uji linearitas adalah untuk mengetahui hubungan antara variabel bebas dan variabel terikat apakah mempunyai hubungan linear atau tidak. Linearitas merupakan persyaratan mutlak bagi analisis regresi karena pada dasarnya regresi yang signifikan menunjukkan adanya linearitas (hubungan linear) antara variabel bebas dan terikat. Kriteria pengujian linearitas adalah jika nilai signifikansi pada linearity kurang dari $0,05(p<0,05)$, maka hubungan antarvariabel bebas dan variabel terikat linear. Uji linearitas dilakukan dengan menggunakan bantuan program SPSS 17.0

\section{c. Uji Multikolinearitas}

Multikolinearitas adalah adanya korelasi positif yang sangat tinggi di antara variabel bebas.Artinya, antara variabel independent (variabel bebas) memiliki hubungan yang sempurna atau mendekati sempurna. Konsekuensi adanya multikolinearitas dalam model regresi adalah kesalahan standar estimasi akan cenderung meningkat dengan bertambahnya variabel independen, tingkat signifikansi yang digunakan untuk menolak hipotesis nol akan semakin besar dan probabilitas menerima hipotesis yang salah menjadi semakin besar.

Untuk menguji terjadinya multikolinearitas digunakan analisis korelasi dengan bantuan program SPSS for Windows versi 17.0. Pedoman pengambilan keputusan didasarkan pada pendapat Field (2009: 224) yang menyatakan hubungan (kolerasi) antarvariabel bebas yang lebih besar dari 0,85 dan tidak ada nilai VIF di atas 10.

\section{Uji Hipotesis}

Pengujian hipotesis penelitian dilakukan dengan menggunakan analisis regresi linear sederhana dengan bantuan program SPSS 17.0.Pada hipotesis dapat diperoleh persamaan regresi linear sederhana $Y=a+b X 1$;

\section{HASIL}

Persyaratan analisis regresi merupakan syarat sebelum menentukan seberapa besar kontribusi variabel bebas terhadap variabel terikat.Uji yang dilakukan, yaitu 1) normalitas,

2) linearitas, dan 3) multikolinearitas.

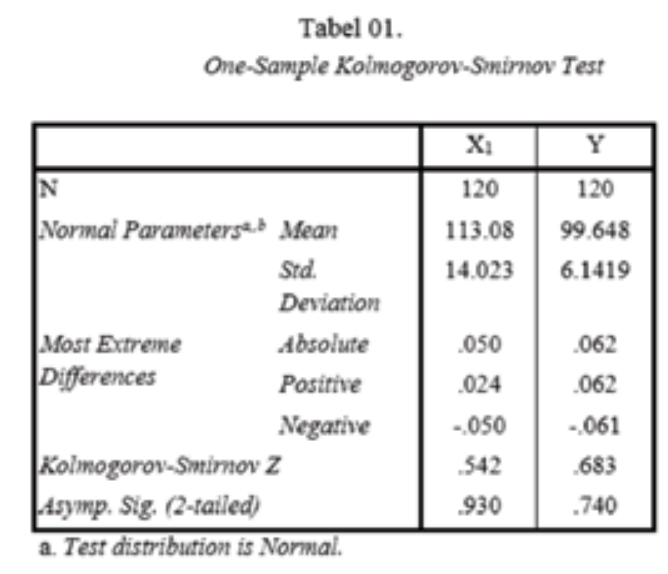

Berdasarkan hasil perhitungan Kolmogorov-Smirnov (a) di atas (lihat Tabel 19 Asymp.Sig dari X1 0,930.Asymp. Sig (2-tailed) $>0,05$, maka variabel bersifat normal sehingga dapat disimpulkan bahwa data kepemimpinan kepala sekolah berdistribusi normal. Berdasarkan hasil perhitungan Kolmogorov-Smirnov(a)di atas (lihat Tabel 19), asymp.Sig dari Y0,740; Asymp. Sig (2-tailed) > 0,05, maka variabel bersifat normal sehingga dapat disimpulkan bahwa data kinerja guru berdistribusi normal.

2. Uji Linearitas 
Linearitas merupakan persyaratan linearitas adalah untuk mengetahui hubungan mutlak bagi analisis regresi karena pada antara variabel bebas dan variabel terikat dasarnya regresi yang signifikan menunjukkan apakah mempunyai hubungan linear atau adanya linearitas (hubungan linear) antara tidak.Uji linearitas dapat ditunjukkan dalam variabel bebas dan variabel terikat.Tujuan uji tabel berikut (Tabel 20 \& 21).

Tabel 02.

Uji Linearitas Variabel Kepemimpinan Kepala Sekolah Terhadap Kinerja Guru

ANOVA Table

\begin{tabular}{|cc|c|c|c|c|c|}
\hline & & $\begin{array}{c}\text { Sum of } \\
\text { Squares }\end{array}$ & df & $\begin{array}{c}\text { Mean } \\
\text { Square }\end{array}$ & F & Sig. \\
\hline $\mathrm{Y}^{*} \mathrm{X}_{1}$ Between Groups & (Combined) & 3415.878 & 51 & 66.978 & 4.244 & .000 \\
& Linearity & 2079.694 & 1 & 2079.694 & 131.778 & .000 \\
& $\begin{array}{c}\text { Deviation } \\
\text { from } \\
\text { Linearity }\end{array}$ & 1336.184 & 50 & 26.724 & 1.693 & .022 \\
Within Groups & & 1073.162 & 68 & 15.782 & & \\
Total & 4489.040 & 119 & & & \\
\hline
\end{tabular}

Berdasarkan Tabel 20 di atas, hasil perhitungan linearitas untuk kepemimpinan kepala sekolah terhadap kinerja guru diperoleh nilai signifikansi linearity sebesar 0,000. Oleh karena itu, sesuai dengan kriteria probabilitas, maka 0,000 lebih kecil dari 0,05 ( $<<0,05)$ sehingga dapat disimpulkan bahwa terdapat linearitas antara variabel kepemimpinan kepala sekolah (X1) dengan kinerja guru (Y).

\section{Uji Multikolinearitas}

Pendeteksian multikolinearitas dalam penelitian ini dilakukan dengan melihat nilai tolerance dan variance inflation factor (VIF). Indikasi multikolinearitas dalam penelitian ini dapat dilihat pada tabel berikut (Tabel 22).

Tabel 03. Hasil Uji Multikolinearitas

\begin{tabular}{|c|c|c|}
\hline \multicolumn{3}{|c|}{ Coefficients $^{\mathrm{a}}$} \\
\hline \multirow{2}{*}{ Model } & \multicolumn{2}{|c|}{ Collinearity Statistics } \\
\cline { 2 - 3 } & Tolerance & VIF \\
\hline $\mathrm{X}_{1}$ & .957 & 1.045 \\
$\mathrm{X}_{2}$ & .957 & 1.045 \\
\hline
\end{tabular}

a. Dependent Variable: Y 
Berdasarkan hasil analisis yang program SPSS 17.0 untuk menguji pengaruh ditampilkan pada Tabel 22 tersebut terlihat masing-masing variabel bebas terhadap bahwa nilai tolerance lebih besar dari 0,1 variabel terikat, yaitu regresi X1 terhadap dan tidak ada nilai VIF di atas 10. Penanda Y dan regresi X2 terhadap Y (regresi liniear adanya multikolinearitas nilai VIF adalah sederhana) dan pengaruh secara bersamalebih dari 10.Dengan demikian, dapat sama X1 dan X2 terhadap Y (regresi linear disimpulkan bahwa tidak terdapat bukti ganda).

adanya multikolinearitas antarvariabel bebas.

C. Pengujian Hipotesis

Hipotesis yang diuji dalam penelitian ini didasarkan pada uji $\mathrm{F}$ dengan bantuan 24).

Tabel 04. Signifikansi Regresi X1 Terhadap Y

ANOVA $^{b}$

\begin{tabular}{|c|c|c|c|c|c|}
\hline Model & $\begin{array}{l}\text { Sum of } \\
\text { Squares }\end{array}$ & df & Mean Square & $\mathrm{F}$ & Sig. \\
\hline Regression & 2079.694 & 1 & 2079.694 & 101.855 & $.000^{\mathrm{a}}$ \\
\hline Residual & 2409.346 & 118 & 20.418 & & \\
\hline Total & 4489.040 & 119 & & & \\
\hline
\end{tabular}

a. Predictors: (Constant), $\mathrm{X}_{1}$

b. Dependent Variable: Y

Dari Tabel 24 di atas, dapat diperoleh nilai signifikansi regresi linear sederhana X1 terhadap Y sebesar $0,000(p<0,05)$. Hal ini kepemimpinan kepala sekolah (X1) terhadap variabel kinerja guru (Y).

berarti regresi linear sederhana $\mathrm{X} 1$ terhadap Analisis regresi linear sederhana $\mathrm{Y}$ adalah signifikan.Artinya $\mathrm{H} 0$ ditolak. Dengan demikian, dapat disimpulkan bahwa ada pengaruh positif signifikan variabel

Uji hipotesis I menggunakan analisis regresi linear sederhana dengan bantuan SPSS 17.0 dapat dilihat dalam tabel berikut (Tabel

Tabel 05. Koefisien Regresi X1 terhadap Y

Coefficients $^{\mathrm{a}}$

\begin{tabular}{|c|c|c|c|c|c|}
\hline \multirow[b]{2}{*}{ Model } & \multicolumn{2}{|c|}{$\begin{array}{c}\text { Unstandardized } \\
\text { Coefficients }\end{array}$} & \multirow{2}{*}{\begin{tabular}{|c|}
$\begin{array}{c}\text { Standardized } \\
\text { Coefficients }\end{array}$ \\
Beta
\end{tabular}} & \multirow[b]{2}{*}{$\mathrm{T}$} & \multirow[b]{2}{*}{ Sig. } \\
\hline & B & Std. Error & & & \\
\hline $\begin{array}{l}\text { (Consta } \\
\text { it) }\end{array}$ & 65.940 & 3.365 & & 19,594 & .000 \\
\hline $\mathrm{x} 1$ & .298 & .030 & .681 & 10,092 & .000 \\
\hline
\end{tabular}

a. Dependent Variable: Y 
Berdasarkan Tabel 25 di atas, dapat diketahui koefisien regresinya sebesar 0,298 dan konstanta sebesar 65,940, dengan demikian, arah regresinya positif. Selanjutnya, dapat dideskripsikan persamaan regresi sesuai dengan rumus persamaan regresi, yaitu $\mathrm{y}^{\wedge}=65,940+0,298 \mathrm{X} 1$. Artinya, semakin bertambah nilai kepemimpinan kepala sekolah (X1), maka semakin bertambah pula nilai kinerja guru (Y). Dengan perkataan lain, kepemimpinan kepala sekolah dapat meningkatkan kinerja guru.

Berdasarkan output SPSS 17.0 dapat diketahui besarnya kontribusi variabel X1 terhadap Y dapat dilihat dalam tabel berikut (Tabel 26).

Tabel 06.

Tabel Kontribusi Variabel X1 Terhadap Y

\begin{tabular}{|c|c|c|c|c|}
\hline Model Summary \\
\hline Model & $\mathrm{R}$ & R Square & $\begin{array}{c}\text { Adjusted } R \\
\text { Square }\end{array}$ & $\begin{array}{c}\text { Std. Error of } \\
\text { the Estimate }\end{array}$ \\
\hline 1 & $.681^{2}$ & .463 & .459 & 4.5186 \\
\hline
\end{tabular}

a. Predictors: (Constant), $\mathrm{X}_{1}$

b. Dependent Variable: Y

Berdasarkan Tabel 26 di atas, dapat diperoleh besarnya koefisien determinasi (R2) sebesar 0,463. Hal ini berarti besarnya kontribusi variabel kepemimpinan terhadap kinerja guru sebesar 46,3\%, sisanya 53,7\% dipengaruhi oleh faktor lain.

\section{PEMBAHASAN}

1. Pengaruh Kepemimpinan Kepala Sekolah Terhadap Kinerja Guru

Hasil penelitian ini membuktikan bahwa ada pengaruh kepemimpinan kepala sekolah terhadap kinerja guru dengan signifikannya uji regresi (p) sebesar 0,000 $(\mathrm{p}<0,05)$, artinya H0 ditolak. Hal ini menunjukkan adanya pengaruh signifikan kepemimpinan kepala sekolah terhadap kinerja guru. Koefisien determinasi sebesar 0,463 menunjukkan kontribusi kepemimpinan kepala sekolah terhadap kinerja guru SMA di Kabupaten Sumba Barat Daya NTT sebesar $46,3 \%$, sisanya $53,7 \%$ dipengaruhi oleh faktor lain. Hal ini membuktikan bahwa aspekaspek kepemimpinan transformasional kepala sekolah mampu memberikan kontribusi positif signifikan terhadap kinerja guru SMA di Kabupaten Sumba Barat Daya NTT.

Hasil penelitian ini dapat menegaskan bahwa semakin bertambah nilai X1, semakin bertambah pula nilai Y. Hal ini dapat dimaknai bahwa semakin bertambah nilai kepemimpinan kepala sekolah (X1), maka semakin bertambah pula nilai kinerja guru (Y). Dengan rumusan lain, semakin bertambah kualitas kepemimpinan kepala sekolah, maka semakin meningkat atau bertambah tinggi kinerja guru.

Berpijak pada hasil penelitian di atas, secara teoretis menunjukkan bahwa kepemimpinan kepala sekolah memiliki peran penting dalam organisasi sekolah untuk mempengaruhi para guru, tenaga kependidikan dan semua stakeholder melalui kemampuan meyakinkan oranglaintentangnilai,norma, dankepercayaan dalam visi sekolah, menggerakkan dan memajukan aktivitas mereka untuk mencapai tujuan organisasi sekolah. Karena itu, kepala sekolah harus memiliki pengetahuan yang memadai tentang tugas di sekolah, memahami keterkaitan antara berbagai unit kerja, memahami kebutuhan dan relasi antarguru, memiliki wawasan tentang organisasi, peraturan perundang-undangan, dan prosedurprosedur kerja, mampu membangun semangat kerja para guru, pegawai, dan peserta didik, menciptakan suasana lingkungan sosial dan 
fisik yang nyaman, dan mampu mengatasi berbagai masalah yang terjadi di sekolah.

Fungsi

kepemimpinan

transformasional kepala sekolah dapat membantu kepala sekolah menjalankan perannya secara efektif di tengah tuntutan perubahan yang menekankan kualitas layanan pendidikan. Fungsi kepemimpinan tersebut meliputi aspek charisma, idealized influence, inspirational motivation, intellectual stimulation, dan individual consideration. Kepala sekolah yang mengembangkan aspek-aspek fungsi kepemimpinan tersebut dalam perannya sebagai kepala sekolah dapat memberikan kontribusi terhadap kinerja guru dan pegawai di sekolahnya untuk mencapai tujuan pendidikan.

Kepemimpinan yang efektif dapat tercipta apabila kepala sekolah memiliki sifat, perilaku dan keterampilan yang baik untuk memimpin sebuah sekolah. Dalam perannya sebagai pemimpin, kepala sekolah harus mampu untuk mempengaruhi semua orang yang terlibat dalam proses pendidikan yaitu guru, para murid, dan iklim sekolah yang akhirnya dapat meningkatkan mutu sekolah. Indikator kepemimpinan yang baik, yaitu 1) Ketegasan dalam mengambil keputusan; 2) Kecerdasan; 3) Kemampuan sebagai pengawas; 4) Stabilitas emosi; 5) Objektivitas; 6) Keterampilan berkomunikasi; dan 7) Keterampilan sosial.

\section{DAFTAR PUSTAKA}

Dick Hartoko.

(1987) Memanusiakan manusia muda. Yogyakarta: Kanisius.

Depdiknas.

(2008). Peraturan Pemerintah RI Nomor, 78 Tahun
2008, tentang Kompetensi Guru.

Depdiknas.

(2005). Undang-Undang RI Nomor 14, Tahun 2005, tentang Guru dan Dosen.

Depdiknas.

(2003). Undang-Undang RI Nomor 20, Tahun 2003, tentang Sistem Pendidikan Nasional.

Esthon Funai.

(2012). UN SMA/SMK 2012, NTT Raih

Posisi Terakhir.Diambil pada tanggal

27 Mei 2012.http://www.wartasemesta. com/un-smasmk-2012.

Field, Andy.

(2009). Discovering statistics using spss tand sex and drugs and rock n' roll). California: Sage.

Joko Sulistyos.

(2010). 6 hari jago SPSS 17.Yogyakarta:

Cakrawala.

Ngainun Naim.

(2009). Menjadi guru inspiratif.

Yogyakarta: Pustaka Pelajar.

Sagala, Syaiful.

(2009). Kemampuan profesional guru dan tenaga kependidikan.Bandung: Alfa Beta.

Saiful Bahri.

(2010). Optimalisasi kinerja kepala sekolah.Jakarta: Gibon Books.

Peringkat indeks pengembangan manusia 2011.Diambil tanggal 19 Mei 2012.http://hdr.undp.org/en/media/ HDR-2011). 